\title{
The impact of supply chain relationship quality on brand promise
}

\author{
Fatemeh Nehzat ${ }^{*}$
}

Department of Management, Payame NoorUniversity, Alborz, Iran

\section{H R O N I C L E ABSTRACT}

Article history:

Received July 18, 2014

Accepted December 182014

Available online

December 232014

Keywords:

Brand promise

Supply chain management

Quality

\begin{abstract}
This paper investigates the role of quality of supply chain components on brand promise. The dimensions of supply chain relationships include: communication, cooperation, commitment, independence, adaptability and reliability. The study uses the questionnaire developed by Fynes et al. (2005) [Fynes, B., Voss, C., \& de Búrca, S. (2005). The impact of supply chain relationship quality on quality performance. International Journal of Production Economics, 96(3), 339-354.]. The population of the study includes all auto part makers and the study chooses a sample of 384 people for the study. Using structural equation modeling, the study has confirmed that all six components influence positively on brand promise.
\end{abstract}

\section{Introduction}

During the past few decades, the nature of supply chain (SC) relationships has changed, significantly. Many firms have been encouraged to have close partnerships with their suppliers as well as their customers. At the same time, most companies have also been exhorted to apply quality management (QM) techniques to survive (Sitkin et al., 1994). Li et al. (2006) investigated the effect of supply chain management (SCM) practices on competitive advantage and organizational performance. They believe effective SCM has become a valuable way of securing competitive advantage and contributing to organizational performance among supply chains. Li et al. (2006) conceptualized and developed five dimensions of SCM practice; namely strategic supplier partnership, customer relationship, level of information sharing, quality of information sharing, and postponement and examined the relationships between SCM practices, competitive advantage, and organizational performance. They collected the necessary data from 196 firms and the relationships proposed in the framework were examined using structural equation modeling. They reported that higher levels of SCM practice could lead to enhanced competitive advantage and improved organizational performance. Moreover, competitive advantage could have a direct, positive effect on organizational performance.

\footnotetext{
* Corresponding author

E-mail address: nehzat.fatima@gmail.com (F. Nehzat)

(C) 2015 Growing Science Ltd. All rights reserved. doi: $10.5267 /$ j.uscm.2014.12.007
} 
According to Kannan and Tan (2005), just in time, SCM, and quality management, have received considerable attention, while they are viewed and applied as if they were independent and distinct, they can also be applied as three components of an integrated strategy. Kannan and Tan (2005) empirically investigated the extent to which just in time, SCM, and quality management were correlated, and how they influence business performance. They reported that at both strategic and operational levels, there were some relationships between how just in time, total quality management, and SCM were viewed by firms as part of their operations strategy. Their results also indicated that a commitment to quality and an understanding of supply chain dynamics had the biggest effect on performance.

Building a good brand also plays essential role for the success of business units (Kiddon \& Light, 2009) and there are many studies to learn how to build a good brand (Clottey et al., 2011). According to Samiei Nasr et al. (2014), accomplishing of the promises or brand promise plays an important role for the success of organizations. They presented an empirical investigation to evaluate the rate of management's interest and personnel's motivation in an Iranian firm named TAM Iran Khodro. The study reviewed its relationship with fulfillment of corporative promises for customers by selecting a sample of 206 employees of TAM Iran Khodro Company. They reported that management's tendency and personnel's motivation were positively and significantly associated with fulfillment of corporative promises to customers (Brand Promise) with correlation coefficient 0.427. Abbasi et al. (2014) investigated the effects of four components of organizational culture on brand promise in one of Iranian producer of detergent and sanitary products. The study detected that three components of organizational culture including tribal culture, entrepreneurial culture, and market culture could influence positively on brand promise and bureaucratic culture could influence negatively on brand promise. Aziziha et al. (2014) studied the impact of various conflict management strategies including competition, cooperation, prevention and compromise on brand promise based on a survey of Putnam and Wilson (1982). The study was executed among some employees of bank Melli Iran in city of Tehran, Iran. Cronbach alphas have been calculated as 0.76 and 0.83 for conflict management and brand promise, respectively. The study reported that there was a reverse relationship between two conflict management strategies, cooperation and compromise, and brand promise. In addition, there was a positive relationship between two conflict management strategies, competition and compromise, and brand promise. Burmann and Zeplin (2005) proposed holistic model for internal brand management.

\section{The proposed study}

This paper investigates the role of quality of supply chain components on brand promise. The dimensions of supply chain relationships include: communication, cooperation, commitment, independence, adaptability and reliability. The study uses the questionnaire developed by Fynes et al. (2005). Fig. 1 demonstrates the structure of the proposed study,

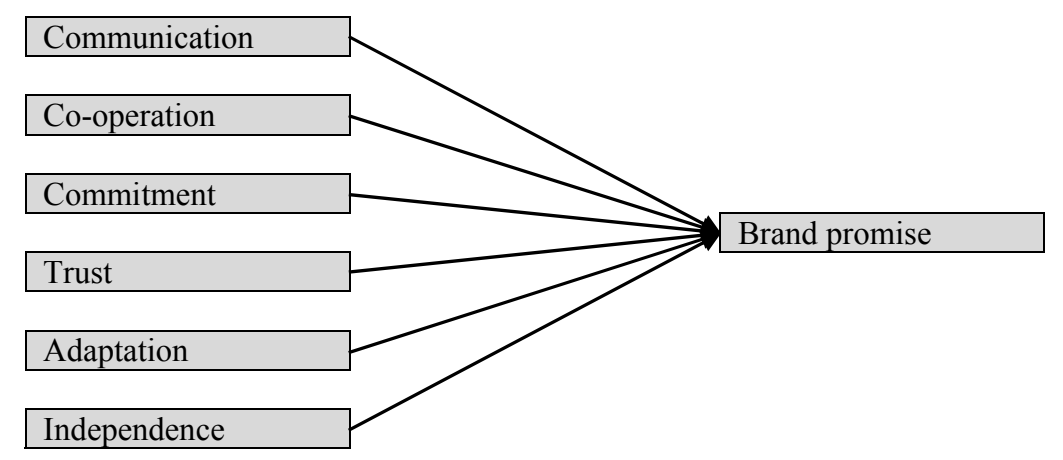

Fig. 1. The proposed study

According to Fig. 1, the following six hypotheses are considered, 
1. There is a meaningful relationship between trust and brand promise.

2. There is a meaningful relationship between adaptation and brand promise.

3. There is a meaningful relationship between communication and brand promise.

4. There is a meaningful relationship between independency and brand promise.

5. There is a meaningful relationship between commitment and brand promise.

6. There is a meaningful relationship between cooperation and brand promise.

The population of the study includes all auto part makers and the study chooses a sample size as follows,

$$
N=Z_{\alpha / 2}^{2} \frac{p \times q}{e^{2}},
$$

where $N$ is the sample size, $p=1-q$ represents the probability, $z_{\alpha / 2}$ is CDF of normal distribution and finally $\varepsilon$ is the error term. For our study we assume $p=0.5, z_{\alpha / 2}=1.96$ and $e=0.05$, the number of sample size is calculated as $N=384$. The study chooses a sample of 385 people who were involved in auto part industry and distributes the sample size among them. In our survey, $27.8 \%$ of the participants were female and $72.2 \%$ of them were male. In addition, $41.3 \%$ of them were middle level managers and $58.7 \%$ of them were regular employees. Fig. 2 shows other personal characteristics of the participants.

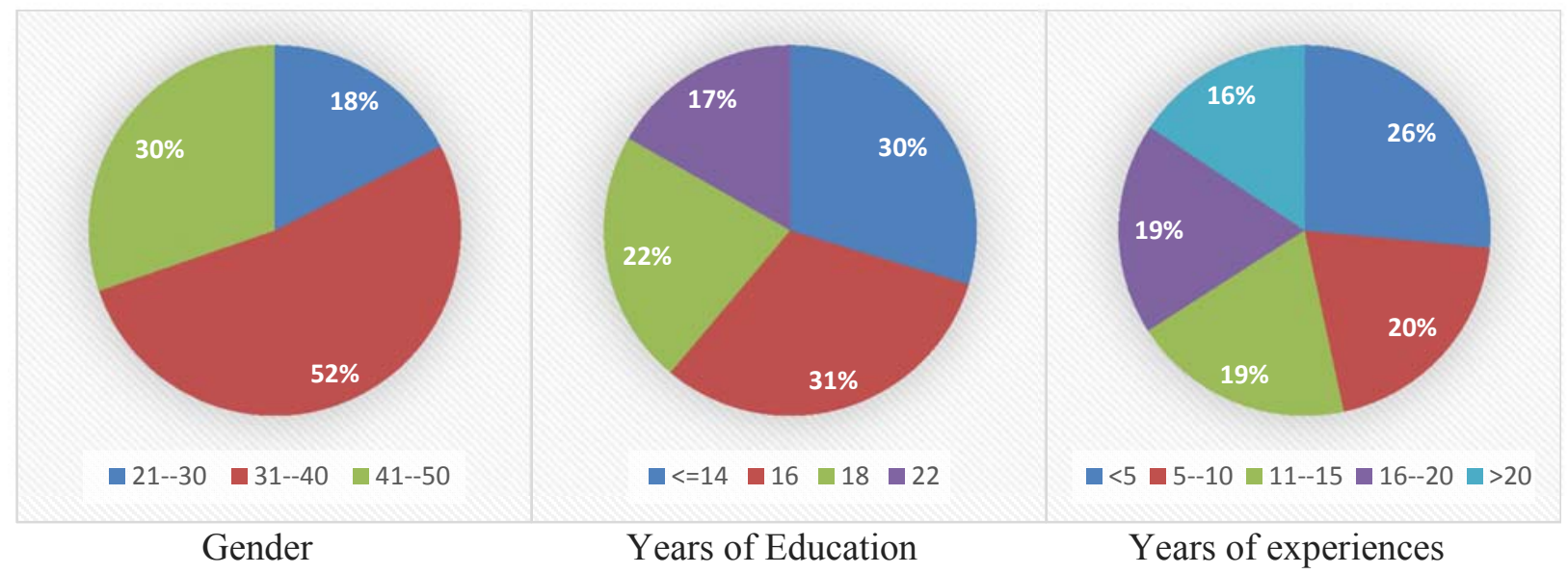

Fig. 1. Personal characteristics of the participants

\section{The results}

In this section, we present details of the implementation of structural equation modeling for testing various hypotheses of the survey. The study uses structural equation modeling to examine the effects of various variables on brand promise. Fig. 3 demonstrates the results of standard coefficients. As we can observe from the results of Fig. 3, Chi-Square value is equal to 844.25 with $\mathrm{P}$-value $=0.000$, which confirms the model. In addition, The Root Mean Square Error of Approximation (RMSEA) is equal to 0.067 , which is also within acceptable level. Table 1 demonstrates other statistical observations. 


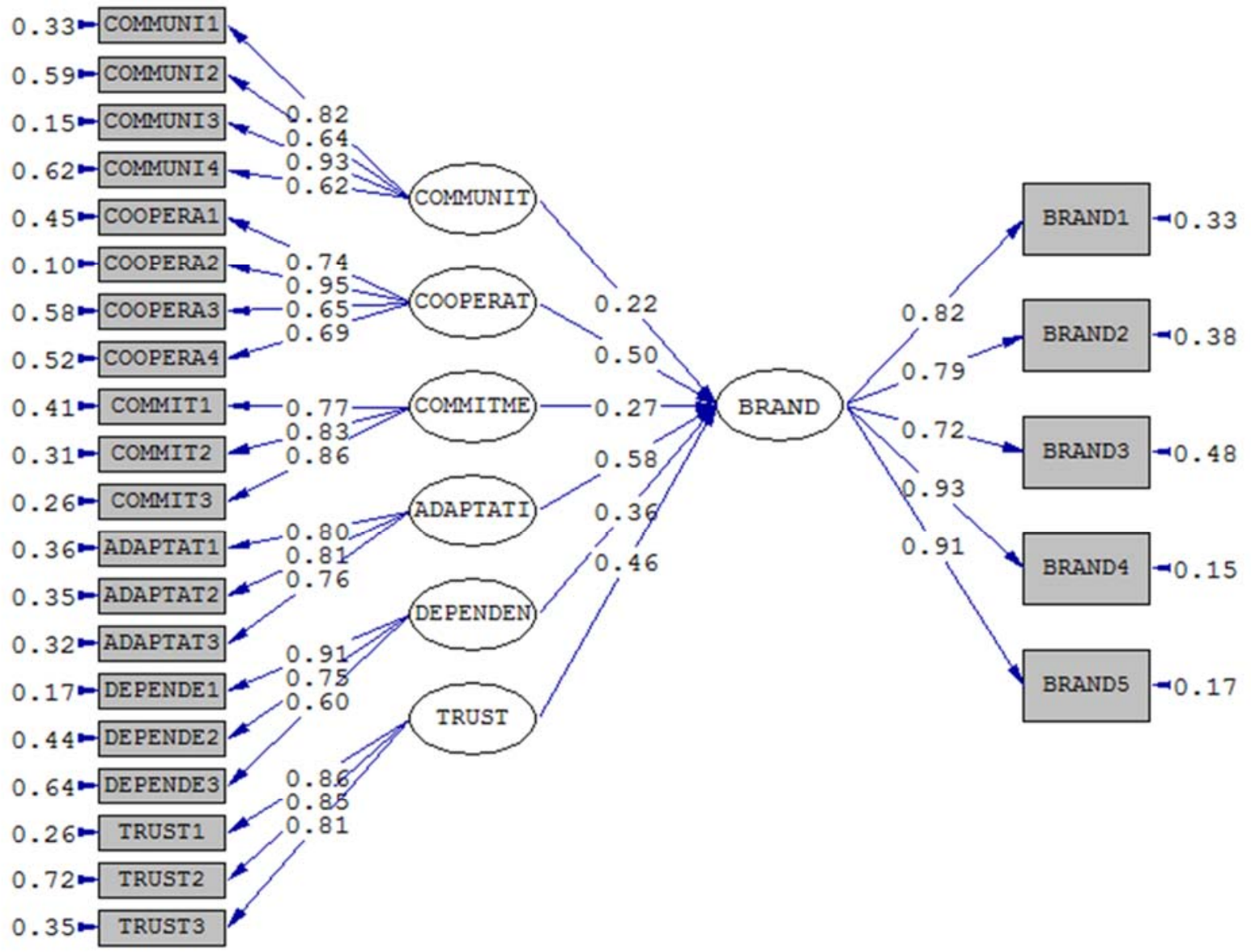

Chi-Square $=844.25, d f=364, \mathrm{P}-\mathrm{value}=0.00000, \mathrm{RMSEA}=0.067$

\section{Table 1}

Fig. 3. The results of standard coefficients

The summary of some statistics associated with the implementation of structural equation modeling

\begin{tabular}{ccccccccc}
\hline Chi-square & $(\mathrm{df})$ & Chi-Square/df & P-value & RMSEA & GFI & PGFI & CFI & NFI \\
\hline 844.25 & 364 & 2.32 & $\mathrm{P}<0.05$ & 0.067 & 0.94 & 0.67 & 0.91 & 0.90 \\
\hline
\end{tabular}

Now, we present details of the implementation of testing hypotheses of the survey. Table 2 presents the standard coefficients as well as t-student values.

Table 2

The summary of standard coefficients along with t-student values

\begin{tabular}{lccc}
\hline Relationship & Standard coefficient & t-value & Result \\
\hline Communication $\rightarrow$ Brand promise & $0.22^{* *}$ & 2.71 & Confirmed \\
Co-operation $\rightarrow$ Brand promise & $0.50^{* *}$ & 5.94 & Confirmed \\
Commitment $\rightarrow$ Brand promise & $0.27^{* *}$ & 3.55 & Confirmed \\
Adaptability $\rightarrow$ Brand promise & $0.58^{* *}$ & 6.11 & Confirmed \\
Independence $\rightarrow$ Brand promise & $0.36^{* *}$ & 3.98 & Confirmed \\
Trust $\rightarrow$ Brand promise & $0.46^{* *}$ & 4.14 & Confirmed \\
\hline $\mathrm{P}<0.01$ & & &
\end{tabular}


As we can observe from the results of Table 2, all components of the survey positively influence on brand promise when the level of significance is one percent. In our survey, adaptability maintains the highest impact followed by cooperation and trust.

\section{Conclusion}

In this survey, we have performed an empirical investigation to study the impact of six factors; namely, communication, cooperation, commitment, adaptability, independence and trust on building a good brand promise. The results of the survey have concluded that supply chain management plays essential role for development a successful business plan. It is important to reach a sustainable supply chain by detecting customers' needs and requirements. Supply chain members have to resolve any existing conflict of interest throughout the supply chain. Trust may create competitive advantage between suppliers and organization and could boost sales figures. Therefore, there is a need to create a common objective among suppliers and firms. In our survey, continuous interaction among members of the supply chain may lead to greater value throughout the supply chain network. The members of supply chain have to understand that the continued activities of each member of the supply chain depends entirely on the activity of other members. This idea could help members of suppliers resolve any existing issues within the supply chain and all members will benefit the positive consequences of the event. Commitment among members of the supply chain influence the organization's brand promise. Commitment is necessary for the survival and continuity of communication among members of the supply chain. In such organization, each member believes that any challenges in the firm could create troubles for anyone. Commitment among members of the supply chain will ultimately lead to the development of sustainable competitive advantage and customer satisfaction. This is consistent with findings of earlier results given by Fynes et al. (2005), Heding et al. (2008) and Pringle (2008).

\section{Acknowledgement}

The authors would like to thank the anonymous referees for constructive comments on earlier version of this paper.

\section{References}

Abbasi, H., Abbasi, H., Faraji, A \& Hajirasouliha, M. (2014). Investigating the effects of organizational culture on brand promise. Management Science Letters, 4(5), 1039-1042.

Aziziha, H., Mousavi, S., Tabatabaee, S \& Khodsetan, A. (2014). Investigating the effect of different conflict management strategies on brand promise: A case study of banking industry. Management Science Letters, 4(1), 1-4.

Burmann, C., \& Zeplin, S. (2005). Building brand commitment: A behavioural approach to internal brand management. The Journal of Brand Management, 12(4), 279-300.

Clottey, T. A., Collier, D. A., \& Stodnick, M. (2011). Drivers of customer loyalty in a retail store environment. Journal of Service Science (JSS), 1(1), 35-48.

Fynes, B., Voss, C., \& de Búrca, S. (2005). The impact of supply chain relationship quality on quality performance. International Journal of Production Economics, 96(3), 339-354.

Heding, T., Knudtzen, C. F., \& Bjerre, M. (2008). Brand management: Research, theory and practice. Routledge.

Kannan, V. R., \& Tan, K. C. (2005). Just in time, total quality management, and supply chain management: understanding their linkages and impact on business performance. Omega, 33(2), 153162.

Kiddon, J., \& Light, L. (2009). Six Rules for Brand Revitalization: Learn how Companies Like McDonald's Can Re-energize Their Brands. Wharton School Publishing. 
Li, S., Ragu-Nathan, B., Ragu-Nathan, T. S., \& Subba Rao, S. (2006). The impact of supply chain management practices on competitive advantage and organizational performance. Omega, 34(2), 107-124.

Putnam, L. L., \& Wilson, C. E. (1982). Communicative strategies in organizational conflicts: Reliability and validity of a measurement scale. Communication yearbook, 6, 629-652.

Pringle, H. (2008). Brand immortality: How brands can live long and prosper. Kogan Page Publishers.

Samiei Nasr, M., Mahmoudzadeh, S., Mousavi, S \& Boostani, A. (2014). The role of management's tendency and personnel's motivation in fulfillment of brand promise. Management Science Letters, 4(6), 1077-1084.

Sitkin, S. B., Sutcliffe, K. M., \& Schroeder, R. G. (1994). Distinguishing control from learning in total quality management: a contingency perspective. Academy of management review, 19(3), 537-564. 